Working Paper/Document de travail

2008-26

\title{
Price-Level versus Inflation Targeting with Financial Market Imperfections
}

by Francisco Covas and Yahong Zhang 
Bank of Canada Working Paper 2008-26

August 2008

\title{
Price-Level versus Inflation Targeting with Financial Market Imperfections
}

by

\author{
Francisco Covas $^{1}$ and Yahong Zhang ${ }^{2}$ \\ ${ }^{1}$ Division of Banking Supervision and Regulation \\ Federal Reserve Board \\ 20th Street and Constitution Avenue \\ NW, Washington, DC 20551, U.S.A. \\ Francisco.B.Covas@frb.gov \\ ${ }^{2}$ Monetary and Financial Analysis Department \\ Bank of Canada \\ Ottawa, Ontario, Canada K1A OG9 \\ yzhang@bankofcanada.ca
}

Bank of Canada working papers are theoretical or empirical works-in-progress on subjects in economics and finance. The views expressed in this paper are those of the authors.

No responsibility for them should be attributed to the Board of Governors of the Federal Reserve System or the Bank of Canada. 


\section{Acknowledgements}

This paper started when Francisco Covas was a senior analyst at the Bank of Canada. We are grateful for insightful suggestions from Miguel Molico. We have also benefited from extensive discussions with Carlos De Resende, Caterina Mendicino, Rhys Mendes, and Shin-Ichi Nishiyama. We thank Alan Crawford, Ali Dib, Walter Engert, Giovanni Lombardo, Cesaire Meh, Nooman Rebei and Masashi Saito for useful comments. We also thank Thomas Carter for his input. 


\begin{abstract}
This paper compares price-level-path targeting (PT) with inflation targeting (IT) in a sticky-price, dynamic, general equilibrium model augmented with imperfections in both the debt and equity markets. Using a Bayesian approach, we estimate this model for the Canadian economy. We show that the model with both debt and equity market imperfections fits the data better and use it to compare PT versus the estimated current IT regime. We find that in general PT outperforms the current IT regime. However, the gain is lower when financial market imperfections are taken into account.

JEL classification: E40, E50

Bank classification: Monetary policy framework; Inflation targets; Economic models
\end{abstract}

\title{
Résumé
}

L'étude compare une règle comportant une cible de niveau des prix à une règle axée sur la poursuite d'une cible d'inflation, dans le cadre d'un modèle dynamique d'équilibre général à prix rigides qui intègre des marchés obligataire et boursier imparfaits. À l'aide d'une approche bayésienne, les auteurs estiment ce modèle pour l'économie canadienne. Ils montrent qu'un modèle qui présuppose la présence d'imperfections sur ces deux marchés décrit mieux les données et se servent du modèle estimé pour comparer un régime ciblant le niveau des prix au régime actuel de cibles d'inflation. De façon générale, le régime prenant pour cible le niveau des prix s'avère supérieur au régime actuel, mais sa supériorité est moins marquée lorsque l'imperfection des marchés financiers est prise en compte.

Classification JEL : E40, E50

Classification de la Banque : Cadre de la politique monétaire; Cibles en matière d'inflation; Modèles économiques 


\section{Introduction}

This paper studies the implications of financial market imperfections for the design of monetary policy rules in a standard New Keynesian economy. Currently, Canada follows an inflation targeting (IT) rule, but there is much interest in the advantages and disadvantages of moving to a price-level-path targeting (PT) regime. The conventional wisdom (e.g., Duguay (1994)) about price-level targeting is that it offers lower longterm variability in the price level at the cost of higher short-term variation in inflation and output. Recently, several papers have challenged this conventional view (Svensson (1999), Vestin (2006)). In particular, Vestin (2006) shows that PT dominates IT when agents are forward-looking. Under a PT regime these agents would set prices taking into consideration that higher-than-expected inflation will be followed by lower-thanexpected inflation. Thus under this new view, PT can be a free lunch, that is, PT can deliver both lower long-term and short-term variability in inflation.

This paper compares these two regimes in a forward-looking model augmented with financial market imperfections in the presence of nominal debt contracts. ${ }^{1}$ First, we show that in general PT can deliver lower long-run and short-run variability in inflation. This confirms the new view in the literature. Second, we compare PT versus IT based on a loss function including both variability in inflation and the output gap. ${ }^{2}$ We show that stabilizing inflation does not necessarily imply a stabilization of the output gap in the presence of financial market frictions. Although PT outperforms the current IT regime in general, the gain is lower when financial market imperfections are present. Output gap throughout the paper refers to the deviation of output from the efficient level which would prevail in a flexible-price economy. ${ }^{3}$ We use the deviation from the efficient output level rather than the steady-state level because in the presence of technology shocks, the efficient level of output varies. It is natural to allow the central bank to recognize this fact when adjusting nominal interest rates.

Our model features sticky prices, money-in-the-utility function, investment adjustment costs, financial market imperfections, and imperfect competition in the producers of final goods. We expand the degree of financial market imperfections in Bernanke et al. (1999). In particular, we assume: (1) entrepreneurs only have access to nominal debt contracts, ${ }^{4}$ and (2) capital producers are financed with equity and subject to equity issuance costs. We expect that assuming one-period debt contracts to be written in nominal terms will generate an additional distortion due to unanticipated changes in the price level (debt-deflation effect). Unexpected changes in the price level have an impact on the real value of firms' liabilities and change the balance sheet conditions of firms. This has an effect on the external finance premium, and in turn, on the response of the real economic activity to shocks (financial accelerator mechanism). Meh et al.

\footnotetext{
${ }^{1}$ For business cycle models with financial market imperfections see, for example, Carlstrom and Fuerst (1997), Bernanke et al. (1999), and Christiano et al. (2003).

${ }^{2}$ Throughout the paper, IT refers to the estimated current IT rule.

${ }^{3}$ See Woodford (2003) for detailed discussions on output gap.

${ }^{4}$ Christiano et al. (2003), Gilchrist and Saito (2006), Christensen and Dib (2008) and Dib et al. (2008) also make this assumption in a financial accelerator model.
} 
(2008) has shown that in the presence of nominal assets, a price-level shock can create redistributions among agents and the extent of redistributions is different under PT than IT. However, their study has not taken into account different sources of business cycle fluctuations and financial market imperfections. The assumption that capital producers are financed with equity is motivated by the fact that firms frequently issue equity and that equity finance does have an important role in firm financing. ${ }^{5}$ We capture the imperfections in the equity market by assuming capital producers face a friction in obtaining equity finance. This friction is characterized by a quadratic function that relates the cost of issuing equity to the amount of equity raised. We also assume that this cost is countercyclical.

We estimate the main structural parameters of the model using Canadian time series. Taking the estimates as the parameters in our benchmark case, we compare the estimated IT with PT by performing stochastic simulations of the model. For the two extensions, we find that having equity issuance costs has important implications for model dynamics, however, debt-deflation effect (generated by having debt contracts written in nominal terms) is not the dominating effect for the dynamics of net worth. We find that variability in inflation under PT is less than under IT. This is because forward-looking agents will adjust prices by to a lesser extent under PT since they expect the monetary authority will offset the current shocks in the future. Rational expectations become automatic stabilizers in this forward-looking model. In fact, this expectation channel is so effective and the variability in price level so low that the nominal interest rate is less volatile under PT. As a result, variabilities in the real interest rate and output gap vary little across the two regimes in our benchmark case.

In order to identify the role of financial market imperfections in the PT versus IT comparison, we estimate two alternative models: one from which equity market frictions have been removed and one from which frictions in both markets have been removed. As compared against these two models, the data favor our benchmark model. We conduct stochastic simulations based on these three different models and we show that relative to the models with financial market frictions, the model without financial market frictions predicts larger reductions in loss function under PT. The intuition behind these results is as follows: in a model where financial market frictions are absent, most of the distortions come from inefficient price dispersions caused by nominal rigidities. Thus stabilizing inflation implies a stabilization of the output gap, and PT is particularly effective. However, in the presence of financial markets imperfections this is not necessarily the case. The agency costs in the debt market and the equity issuance costs in the equity market create additional distortions. Due to these distortions, stabilizing inflation does not necessarily lead to less variability in the output gap. The effectiveness of PT depends on the shock structure. In particular, following an investment-specific shock, these additional distortions cause inflation and the output gap to move in opposite directions. In this case, the monetary authority faces a trade-off between the output

\footnotetext{
${ }^{5}$ For evidence on the United States see work by Fama and French (2005), Jermann and Quadrini (2006), Covas and den Haan (2006), and Levy and Hennessy (2006). For evidence on Canadian firms, see work by Covas and den Haan (2007).
} 
gap and inflation: when monetary authority tries to bring down inflation, the output gap widens. Thus, if this type of shock is a significant source of volatility in economy, a decrease in the volatility of inflation might lead to smaller reduction (or even increase) in the volatility of the output gap, thus reducing the effectiveness of PT. ${ }^{6}$

The organization of the paper is as follows. In the next section, we present the model and in section 3, we discuss the data and estimation strategy. In section 4, we report the estimation results and illustrate the main mechanisms of the model. In section 5, we analyze the PT versus IT using the results from stochastic simulations. Section 6 offers some conclusions.

\section{Model}

\subsection{Households}

The representative household derives utility from consumption, $C_{t}$; real money balances, $M_{t} / P_{t}$; and leisure, $1-H_{t}$, with $0<H<1$. The household owns equity in retailers and supplies labor to entrepreneurs who produce the wholesale goods. The household saves by holding a one-period riskless bond $B_{t}$. The aggregate price is $P_{t}$. Preferences are given by

$$
E_{0} \sum_{t=0}^{\infty} \beta^{t} U\left(C_{t}, H_{t}, \frac{M_{t}}{P_{t}}\right)
$$

with

$$
U\left(C_{t}, H_{t}, \frac{M_{t}}{P_{t}}\right)=e_{t} \log C_{t}-\theta \frac{H_{t}^{1+\gamma}}{1+\gamma}+\varphi \log \frac{M_{t}}{P_{t}},
$$

where $1 / \gamma$ is the labor supply elasticity, and $\theta$ and $\varphi$ are the weights on leisure and real money balance in the utility function. The variable $e_{t}$ is an exogenous preference shock which follows

$$
\log e_{t}=\rho_{e} \log e_{t-1}+\epsilon_{t}^{e}, \quad \epsilon_{t}^{e} \sim \text { i.i.d. } N\left(0, \sigma_{\epsilon^{e}}^{2}\right) .
$$

The representative household is subject to the following budget constraint

$$
C_{t}=\frac{W_{t}}{P_{t}} H_{t}+\Pi_{t}-T_{t}-\frac{M_{t}-M_{t-1}}{P_{t}}-\frac{B_{t}-R_{t-1}^{n} B_{t-1}}{P_{t}}
$$

where $W_{t}$ is the nominal wage that the household receives from the entrepreneurs, $\Pi_{t}$ is the real dividend from retailers, $T_{t}$ is a lump-sum tax, $B_{t-1}$ is the bond held between periods $t-1$ and $t$, and $R_{t-1}^{n}$ is the nominal rate of return on the riskless bond.

The household maximizes its expected lifetime utility equation (1) subject to equation (4). The first-order conditions include

$$
\frac{e_{t}}{C_{t}} \frac{1}{R_{t}^{n}}=\beta E_{t}\left[\frac{e_{t+1}}{C_{t+1}} \frac{P_{t}}{P_{t+1}}\right],
$$

\footnotetext{
${ }^{6}$ Coletti et al. (2008) also finds that PT versus IT comparison is sensitive to the incidence of different types of shocks. However, they do not model financial market imperfections explicitly.
} 
and

$$
\frac{e_{t}}{C_{t}} \frac{W_{t}}{P_{t}}=\theta H_{t}^{\gamma}
$$

\subsection{Entrepreneurs}

As in Bernanke et al. (1999) (herein, BGG) entrepreneurs are risk-neutral and manage the production of wholesale goods. The production function for wholesale goods is given by

$$
F\left(K_{t}^{j}, L_{t}^{j}\right)=\omega_{t}^{j}\left(K_{t}^{j}\right)^{\alpha}\left(z_{t} L_{t}^{j}\right)^{1-\alpha} .
$$

At the end of period $t-1$, entrepreneurs purchase capital $K_{t}^{j}$ and use it in period $t$ to produce wholesale goods with labor $L_{t}^{j}$. Production is subject to two type of shocks: $\omega_{t}$ is the idiosyncratic shock, which is private information to the entrepreneur and is i.i.d across entrepreneurs and time, with mean $E\left[\omega_{t}^{j}\right]=1 ; z_{t}$ is an exogenous technology shock common to all the entrepreneurs which follows

$$
\log z_{t}=\rho_{z} \log z_{t-1}+\epsilon_{t}^{z}, \quad \epsilon_{t}^{z} \sim \text { i.i.d. } N\left(0, \sigma_{\epsilon^{z}}^{2}\right)
$$

Labor consists of both household labor $H_{t}^{j}$ and entrepreneurial labor $H_{t}^{e j}:^{7}$

$$
L_{t}^{j}=\left(H_{t}^{j}\right)^{1-\Omega}\left(H_{t}^{e j}\right)^{\Omega}
$$

Given $K_{t}^{j}$, the demand for both household labor and entrepreneurial labor satisfy the following first-order conditions

$$
(1-\Omega) F_{H_{t}}^{j}=\frac{W_{t}}{P_{W, t}},
$$

and

$$
\Omega F_{H_{t}^{e}}^{j}=\frac{W_{t}^{e}}{P_{W, t}},
$$

where $W_{t}$ and $W_{t}^{e}$ are respectively the nominal wages received by households and entrepreneurs, and $P_{W, t}$ is the nominal price of wholesale goods.

Capital purchased at the end of period $t, K_{t+1}^{j}$, is partly financed from the entrepreneur's net worth, $N_{t+1}^{j}$, and partly from issuing nominal debt, $B_{t}^{j}$ :

$$
Q_{t} K_{t+1}^{j}=N_{t+1}^{j}+\frac{B_{t}^{j}}{P_{t}},
$$

where $Q_{t}$ is the price of capital relative to the aggregate price $P_{t}$. Note, unlike in BGG, that the debt contract in this model is in nominal terms, that is, entrepreneurs sign a debt contract that specifies a nominal interest rate, $R_{t}^{n}$.

The financial market imperfections are similar to those in BGG: because the idiosyncratic shock $\omega_{t}^{j}$ is private information for the borrowers (entrepreneurs), there exists

\footnotetext{
${ }^{7}$ As in Bernanke et al. (1999), each entrepreneur is endowed with $H_{t}^{e}$ units of labor to ensure that new entrepreneurs have some funds to start out.
} 
information asymmetry between borrowers and lenders (financial intermediaries). Due to costly state verification, lenders have to pay an auditing cost to observe the output. In BGG the optimal contract is a standard debt with costly bankruptcy: if the entrepreneur does not default, the lender receives a fixed payment independent of $\omega_{t}^{j}$ but contingent upon the aggregate state; if the entrepreneur defaults, the lender audits and seizes the realized return (net of monitoring costs). The risk premium associated with external funds, $s($.$) , is defined as the ratio of the entrepreneur's cost of external funds to the cost$ of internal funds

$$
s_{t}=\frac{E_{t} R_{t+1}^{k}}{E_{t}\left[R_{t}^{n} \frac{P_{t}}{P_{t+1}}\right]},
$$

where $E_{t} R_{t+1}^{k}$ is the expected rate of return of capital, which is equal to the expected cost of external funds in equilibrium, and $E_{t}\left[R_{t}^{n} \frac{P_{t}}{P_{t+1}}\right]$ is the cost of internal funds. BGG shows that the optimal contract implies that the external finance premium, $s($.$) , depends$ on the entrepreneur's balance sheet position. In particular, the external finance premium increases with leverage, and thus, can be characterized by the reduced-form function

$$
s_{t}=s\left(\frac{Q_{t} K_{t+1}^{j}}{N_{t+1}^{j}}\right),
$$

where $s^{\prime}()>$.0 and $s(1)=1 .^{8}$ The supply curve for external financing or the expected marginal cost of external financing can be obtained by rearranging the terms in equation (13)

$$
E_{t} R_{t+1}^{k}=s_{t} R_{t}^{n} E_{t}\left[\frac{P_{t}}{P_{t+1}}\right]
$$

The expected gross return on capital from periods $t$ to $t+1, E_{t} R_{t+1}^{k}$, depends on the marginal productivity of capital and the capital gain,

$$
E_{t} R_{t+1}^{k}=E_{t}\left[\frac{\frac{P_{t+1}^{W}}{P_{t+1}} F_{K}+Q_{t+1}(1-\delta)}{Q_{t}}\right] .
$$

The demand for capital depends on both the expected return on capital (equation (16)) and the expected cost of external financing (equation (15)). To ensure that entrepreneurs will never accumulate enough funds to finance capital acquisitions entirely out of net worth, following BGG, we assume that they have finite lives. The probability that an entrepreneur survives until the next period is $\eta$.

${ }^{8}$ In estimation, we adopt the following functional form to determine the external finance premium:

$$
s_{t}=\left(\frac{Q_{t} K_{t+1}}{N_{t+1}}\right)^{\chi}
$$

where $\chi>0$. In the steady-state, the external finance premium is determined by equation 13 . 
The aggregate net worth of entrepreneurs at the end of period $t, N_{t+1}$, is the sum of equity held by entrepreneurs surviving from period $t-1$ and the wage income: ${ }^{9}$

$$
N_{t+1}=\eta\left(R_{t}^{k} Q_{t-1} K_{t}-E_{t-1}\left[R_{t}^{k}\right]\left(Q_{t-1} K_{t}-N_{t}\right)\right)+(1-\alpha)(1-\Omega) z_{t} K_{t}^{\alpha} L_{t}^{(1-\alpha) \Omega} .
$$

Equation (17) suggests that the difference between the realized rate of return on capital in period $t, R_{t}^{k}$, and the expected rate of return on capital in the previous period, $E_{t-1} R_{t}^{k}$, is the main source of changes in the entrepreneurial net worth. Since entrepreneurs sign a debt contract that specifies a nominal interest rate in our model, an unanticipated change in inflation will also affect the real cost of debt repayment, and, in turn, the difference between $R_{t}^{k}$ and $E_{t-1} R_{t}^{k}$. Substituting equation (15) into equation (17), we get

$N_{t+1}=\eta\left(R_{t}^{k} Q_{t-1} K_{t}-s_{t-1} R_{t-1}^{n} E_{t-1}\left[\frac{P_{t-1}}{P_{t}}\right]\left(Q_{t-1} K_{t}-N_{t}\right)\right)+(1-\alpha)(1-\Omega) z_{t} K_{t}^{\alpha} L_{t}^{(1-\alpha) \Omega}$,

which implies that an unexpected increase (decrease) in inflation reduces (increases) the real cost of debt repayment and, in turn, increase (decrease) net worth (debt-deflation effect).

Entrepreneurs going out of business will consume their residual equity,

$$
C_{t}^{e}=(1-\eta)\left(R_{t}^{k} Q_{t-1} K_{t}-E_{t-1}\left[R_{t}^{k}\right]\left(Q_{t-1} K_{t}-N_{t}\right)\right)
$$

where $C_{t}^{e}$ is the aggregate consumption of the entrepreneurs who exit in period $t$.

\subsection{Capital producers}

Capital production is assumed to be subject to an investment-specific shock, $x_{t}$. Capital producers purchase the final goods from retailers as investment goods, $I_{t}$, and produce efficient investment goods, $x_{t} I_{t}$. Efficient investment goods are then combined with the existing capital stock to produce new capital goods, $K_{t+1}$. The aggregate capital stock evolves according to:

$$
K_{t+1}=x_{t} I_{t}+(1-\delta) K_{t}
$$

The shock $x_{t}$ follows the first-order autoregressive process:

$$
\log x_{t}=\rho_{x} \log x_{t-1}+\epsilon_{t}^{x}, \epsilon_{t}^{x} \sim \text { i.i.d.N }\left(0, \sigma_{\epsilon^{x}}^{2}\right) .
$$

Capital producers are subject to equity issuance costs. Following Covas and den Haan (2006), we let equity issuance costs, $\Lambda\left(I_{t}, x_{t}\right)$, vary with the shock $x_{t}$ :

$$
\Lambda\left(I_{t}, x_{t}\right)=\lambda\left(x_{t}\right) I_{t}^{2}
$$

\footnotetext{
${ }^{9}$ Note that the wage income for entrepreneurs is quantitatively small.
} 
where

$$
\lambda_{x}<0
$$

This functional form has two features: (1). the cost of issuing equity is quadratic. (2). equity issuance cost is countercyclical. Feature 1 is motivated by the empirical evidence in Altinkiliç and Hansen (2000) that underwriting fees display increasing marginal costs. Feature 2 is used to capture the following consideration: one thing that makes equity issuance costly is investors' concern that a firm has an incentive to issue equity when it has private information that it is overvalued by the market. Choe et al. (1993) argues that this concern is countercyclical. ${ }^{10}$

Capital producers are also subject to a quadratic capital adjustment cost , $\frac{\xi}{2}\left(\frac{I_{t}}{K_{t}}-\right.$ $\delta)^{2} K_{t}$. The profit of capital producers is

$$
\Pi_{t}^{k}=E_{t}\left[Q_{t} x_{t} I_{t}-I_{t}-\frac{\xi}{2}\left(\frac{I_{t}}{K_{t}}-\delta\right)^{2} K_{t}-\Lambda\left(I_{t}, x_{t}\right)\right],
$$

and the first-order condition is

$$
E_{t}\left[Q_{t} x_{t}-1-\xi\left(\frac{I_{t}}{K_{t}}-\delta\right)-\Lambda_{I}\left(I_{t}, x_{t}\right)\right]=0 .
$$

\subsection{Retailers}

There is a continuum of monopolistically competitive retailers of measure 1 . Retailers buy wholesale goods from entrepreneurs and differentiate them at zero cost. Let $Y_{t}(j)$ be the retail good sold by retailer $j$ and let $P_{t}(j)$ be its nominal price. The final good, $Y_{t}$, is the composite of individual retail goods,

$$
Y_{t}=\left[\int_{0}^{1} Y_{j t}^{\frac{\varepsilon-1}{\varepsilon}} d j\right]^{\frac{\varepsilon}{\varepsilon-1}}
$$

and the corresponding price index, $P_{t}$, is given by

$$
P_{t}=\left[\int_{0}^{1} P_{t}(j)^{1-\varepsilon} d z\right]^{\frac{1}{1-\varepsilon}} .
$$

The demand function faced by each retailer is given by

$$
Y_{j t}=\left(\frac{P_{j t}}{P_{t}}\right)^{-\varepsilon} Y_{t}
$$

Following Calvo (1983), each retailer cannot reoptimize prices unless it receives a random signal. The probability of receiving such a signal is $1-\nu$. Thus, in each period, only a fraction of $1-\nu$ of retailers reset their prices, while the remaining retailers keep their prices unchanged. Given the demand function equation (28), the retailer chooses $P_{j t}$ to

\footnotetext{
${ }^{10}$ See more discussion in Covas and den Haan (2006)
} 
maximize its expected real total profit over the periods during which its prices remain fixed:

$$
E_{t} \Sigma_{i=0}^{\infty} \nu \Delta_{i, t+i}\left[\left(\frac{P_{j t}}{P_{t+i}}\right) Y_{j t+i}-m c_{t+i} Y_{j t+i}\right]
$$

where $\Delta_{t, i} \equiv \beta^{i} C_{t+i} / C_{t}$ is the stochastic discount factor and the real marginal cost, $m c_{t}$, is the price of wholesale goods relative to the price of final goods $\left(P_{W, t} / P_{t}\right)$. Let $P_{t}^{*}$ be the optimal price chosen by all firms adjusting at time $t$. The first order condition is:

$$
P_{t}^{*}=\left(\frac{\varepsilon}{\varepsilon-1}\right) \frac{E_{t} \sum_{i=0}^{\infty} \nu^{i} \Delta_{i, t+i} m c_{t+1} Y_{t+i}\left(\frac{1}{P_{t+i}}\right)^{-\varepsilon}}{E_{t} \sum_{i=0}^{\infty} \nu^{i} \Delta_{i, t+i} Y_{t+i}\left(\frac{1}{P_{t+i}}\right)^{1-\varepsilon}}
$$

The aggregate price evolves according to:

$$
P_{t}=\left[\nu P_{t-1}^{1-\varepsilon}+(1-\nu)\left(P_{t}^{*}\right)^{1-\varepsilon}\right]^{\frac{1}{1-\varepsilon}}
$$

\subsection{Aggregation and equilibrium}

We assume that the newly created money is transferred to households, so that $T_{t}=$ $M_{t}-M_{t-1}$.

The resource constraint for final goods is

$$
K_{t}^{\alpha}\left(z_{t} L_{t}\right)^{1-\alpha}=C_{t}+C_{t}^{e}+I_{t}+\frac{\xi}{2}\left(\frac{I_{t}}{K_{t}}-\delta\right)^{2} K_{t}+\Lambda\left(I_{t}, x_{t}\right)
$$

However, this restriction is not valid in this model. Price stickiness induces price dispersion across final goods, and this price dispersion is inefficient and causes output loss. Thus, when aggregating, we need to make some adjustment to take into account this inefficiency. To see this, consider the equilibrium condition at the firm level:

$$
F\left(K_{j t}, L_{j t}\right)=\left(C_{t}+C_{t}^{e}+I_{t}+\frac{\xi}{2}\left(\frac{I_{t}}{K_{t}}-\delta\right)^{2} K_{t}+\Lambda\left(I_{t}, x_{t}\right)\right)\left(\frac{P_{j t}^{*}}{P_{t}}\right)^{-\varepsilon},
$$

when integrating over all firms, we obtain

$$
F\left(K_{t}, L_{t}\right)=\left(C_{t}+C_{t}^{e}+I_{t}+\frac{\xi}{2}\left(\frac{I_{t}}{K_{t}}-\delta\right)^{2} K_{t}+\Lambda\left(I_{t}, x_{t}\right)\right) \int_{0}^{1}\left(\frac{P_{j t}^{*}}{P_{t}}\right)^{-\varepsilon}
$$

Let $\Gamma_{t} \equiv \int_{0}^{1}\left(\frac{P_{j t}}{P_{t}}\right) d j$. We can show that

$$
\Gamma_{t}=(1-\nu)\left(\frac{P_{t}^{*}}{P_{t}}\right)^{-\varepsilon}+\nu \pi^{\varepsilon} \Gamma_{t-1} .^{11}
$$

\footnotetext{
${ }^{11}$ See Schmitt-Grohé and Uribe (2006) for details.
} 
Thus, the resource constraint in the model is given by

$$
F\left(K_{t}, L_{t}\right)=\left(C_{t}+C_{t}^{e}+I_{t}+\frac{\xi}{2}\left(\frac{I_{t}}{K_{t}}-\delta\right)^{2} K_{t}+\Lambda\left(I_{t}, x_{t}\right)\right) \Gamma_{t}
$$

where $\Gamma_{t}$ summarizes the resource costs induced by the relative price dispersion. SchmittGrohé and Uribe (2006) show that $\Gamma_{t}$ is bounded below by 1 and has first-order real consequences for the stationary distribution of the endogenous variables if the steadystate inflation is positive.

\subsection{Monetary policy rules}

Inflation targeting. Under an inflation targeting regime, we assume that the central bank operates according to the standard Taylor Rule. The central bank adjusts the nominal interest rate, $R_{t}^{n}$, in response to deviations of inflation, $\pi_{t}$, from its steady-state value, $\pi$, and output, $Y_{t}$, from its efficient level, $Y_{t}^{e}$, which is defined as the level of output that would prevail in the flexible-price economy without financial market imperfections. ${ }^{12}$ We use the deviation from the efficient output level rather than the steady-state level for the following reasons: first, in the presence of technology shocks, the efficient level of output varies. It is natural to allow the central bank to recognize this fact when adjusting nominal interest rates. Second, the efficient output level tends to move in the same direction as output. As a result, if the central bank takes deviation from the steady-state output as an argument in its policy rule, it will tend to set policy that is too contractionary to a positive technology shock and too expansionary to a negative technology shock

$$
\frac{R_{t}^{n}}{R^{n}}=\left(\frac{\pi_{t}}{\pi}\right)^{\phi_{\pi}}\left(\frac{Y_{t}}{Y_{t}^{e}}\right)^{\phi_{Y}} e^{\epsilon_{t}^{m}}
$$

where $R^{n}$ and $\pi$ are the steady-state values of $R_{t}^{n}$ and $\pi_{t}$, and $\varepsilon_{t}^{m}$ is a monetary policy shock which follows

$$
\varepsilon_{t}^{m} \sim \text { i.i.d. } N\left(0, \sigma_{\varepsilon^{m}}\right) .
$$

$\phi_{\pi}$ and $\phi_{Y}$ are policy coefficients chosen by the central bank.

Price-level-path targeting. We assume that by targeting the price level, the central bank adjusts the nominal interest rate, $R_{t}^{n}$, in response to deviations of the price level, $P_{t}$, from the targeted price level $\overline{P_{t}}$ and deviations of the output from its efficient level:

$$
\frac{R_{t}^{n}}{R^{n}}=\left(\frac{P_{t}}{\bar{P}_{t}}\right)^{\phi_{P}}\left(\frac{Y_{t}}{Y_{t}^{e}}\right)^{\phi_{Y}} e^{\epsilon_{t}^{m}}
$$

where $\overline{P_{t}}=\pi^{t} P_{0}$, and $P_{0}=1$.

\footnotetext{
${ }^{12}$ In such an economy, there is no price rigidity nor capital adjustment cost and the external risk premium does not depend on leverage. However, we still assume that firms have to pay risk premium when they go to external financiers. Risk premium is fixed at its steady-state value.
} 


\section{Data and Estimation Strategy}

We adopt a Bayesian approach to estimate the model. We use four series of quarterly Canadian data: output, investment, nominal interest rate and inflation. These series correspond to the vector of observable variables of our model. The sample for our data set spans from 1980Q1 to 2006Q4. Output is measured by real GDP excluding government expenditures because there is no government spending in the model. ${ }^{13}$ Investment is measured by the sum of business gross fixed capital formation and business investment in inventories. The nominal interest rate is measured by the overnight rate. Inflation is calculated from the core CPI. ${ }^{14}$ Data on output and investment are expressed in per capita terms using the civilian population aged 15 and up. Both output and investment series are linearly detrended before estimation. Since a constant inflation target is not plausible for the sample period of 1980Q1 to 2006Q4, we detrend the inflation and nominal interest rate data using the implicit inflation target series from Amano and Murchison (2000).

As is standard when taking DSGE models to the data, we set some parameters prior to estimation because they cannot be identified from the data. The discount factor $\beta$ is set at 0.99, which corresponds to an annual real interest rate in the steady-state at four percent. The steady-state depreciation rate is set to 0.025 , which implies an annual rate of depreciation of ten percent. The parameter of the Cobb-Douglas function, $\alpha$, is set to $1 / 3$. The steady-state price mark up $\varepsilon /(\varepsilon-1)$ is set to 1.1 . We set $\gamma=0.8$ so that the implied labor supply elasticity is $1 / \gamma=1.25$. We set $\theta=0.195$ so that households spend one third of their time working. The survival rate of entrepreneurs, $\eta$, is set to 0.9728 , which is taken from BGG; this implies that the average working life for entrepreneurs is 36 years. The steady-state inflation rate is set to $\pi=0.02$ per year.

For the parameters that we estimate, the first column in Table 2 gives the density, mean and standard deviation of the priors. The elasticity of the external finance premium with respect to firm leverage is set to have a gamma distribution with mean 0.05 , which is close to the estimate in Christensen and Dib (2008), which uses maximum likelihood procedure to estimate a sticky-price model with a financial accelerator on U.S. data.

For the equity issuance cost, we adopt the following functional form:

$$
\Lambda_{t}=\left(\frac{\lambda_{0}}{2 x_{t}^{\lambda_{1}}}\right) I_{t}^{2},
$$

where $\lambda_{0}$ is set to have a gamma distribution with mean 0.75 and standard deviation of 0.1 and the time-varying parameter, $\lambda_{1}$, is set to have a gamma distribution with mean 20 and standard deviation of 2 . This implies that at the steady-state the average equity issuance cost is around 5 percent and the standard deviation of equity issuance cost is around 1 percent, which is consistent with the empirical evidence provided by Covas and den Haan (2006).

\footnotetext{
${ }^{13}$ We do not exclude net exports from the data since they are less than 1 percent of total GDP.

${ }^{14}$ The core CPI is the CPI excluding eight of the most volatile components as well as the effect of changes in indirect taxes on the remaining components). The Bank of Canada uses the core CPI as the basis for its policy actions.
} 
The rest of the priors are standard and follow the literature. For the monetary policy rule, we set the prior of the reaction on inflation, $\phi_{\pi}$, to have a gamma distribution with mean 1.5 and standard deviation 0.1. The coefficient of the reaction on output gap, $\phi_{y}$, is assumed to have a normal distribution of mean 0.1 and standard deviation $0.02 .{ }^{15}$

For the priors of the shocks affecting the economy, we set the autoregressive coefficients of the technology shocks, investment efficiency shocks and preference shocks to have a beta distribution with mean 0.80 and standard deviation 0.05 . The standard deviations of the innovations are assumed to follow an inverse-gamma distribution with a mean of 0.01 .

Finally, following the literature, the parameter $\xi$, which determines the degree of capital adjustment costs, is set to have a normal distribution with mean 0.25 and standard deviation 0.05. The Calvo probability is assumed to be around 0.67, suggesting an average length of price contract of three quarters.

We use Dynare 3.065 to estimate the model. We use the Metropolis-Hasting algorithm to perform simulations. To check convergence, we run two difference chains starting from dispersed points. For each chain, the total number of draws is 100, 000 and the first 20 percent of the draws are neglected. A step size of 0.5 resulted in a rejection rate of 0.36 .

\section{Estimation Results}

\subsection{Parameter estimates}

Table 2 displays the mode, the mean, and the 5 and 95 percentiles of the posterior distribution of the parameters. The prior and posterior distributions of all parameters are shown in Figures 1 and 2. Figure 3 displays the smoothed shocks. Overall, the data seem to be very informative on the exogenous shock processes and the monetary policy parameters. The data appear to be less informative on behavioral parameters, especially $\xi$, the capital adjustment cost parameter, and $\lambda_{1}$, the parameter determining the volatility of equity issuance costs.

In what follows, we report the posterior modes instead of means since they are very close. The elasticity of the risk premium with respect to leverage, $\chi$, is estimated to be around 4 percent. The estimated posterior mode of equity issuance cost parameters, $\lambda_{0}$ and $\lambda_{1}$, are 0.92 and 19.64 respectively. This implies that in the steady-state the average equity issuance cost is around 5.2 percent and the standard deviation of the average equity issuance cost is around 1 percent.

The estimated value of monetary policy parameters, $\phi_{\pi}$, the coefficient which measures the response of monetary policy to deviation of inflation, is 1.3. Given that we set the interest rate smoothing parameter to 0 , this value is quite reasonable. The coefficient that measures the response of monetary policy to output gap, $\phi_{y}$, is 0.015 . This suggests that policy does not appear to react very strongly to output gap.

\footnotetext{
${ }^{15}$ As a robustness check, we also estimate the model with an interest rate smoothing parameter in the monetary policy rule. There is no substantial difference for the main results of the paper.
} 
Turning to the estimates of the parameters for the exogenous shock processes, it turns out that both the investment-specific shock and preference shock are more persistent (0.88 and 0.87 , respectively) than the technology shock (0.76). The preference and technology shocks are more volatile (0.0114 and 0.0147 respectively) than the investmentspecific and monetary policy shocks (0.0057 and 0.0067$)$.

Finally, we turn to the other two parameters, $\xi$ and $\nu$. The estimate of $\xi$, the capital adjustment cost, is 0.26 , which is lower than the estimated value in Christensen and Dib (2008). This suggests that the frictions in the capital production market is partly being captured by the equity issuance costs. The estimate of the sticky price parameter, $\nu$, is 0.42 , suggesting that the average duration of price contracts is about two quarters.

\subsection{Model comparison}

To further access the impact of modeling explicitly the frictions in the debt market and equity market, we estimate two alternative models: one model with debt market frictions but no equity issuance costs, in which we set $\lambda_{0}=\lambda_{1}=0$ (DF model, hereafter), and, one model without frictions in either the debt or equity market, in which we set equity issuance costs to be 0 , turn off the financial accelerator by setting $\chi=0$, and set the external risk premium at its steady-state level (NoFF model, hereafter). We compare the log data densities obtained from these models with that of the benchmark model with both debt and equity frictions (EDF model, hereafter). We also compare the model-implied volatilities and correlations of key variables with the data.

Table 3 presents the estimates of the modes of the parameters and log data densities for the three models. To facilitate the comparison across the three models, the first column reproduces the estimates of the EDF model. Based on log data density, we conclude that the data prefers the EDF model. Table 4 compares the standard deviations and relative volatilities of key variables implied in each model against the data. Although all of the three models generate higher relative volatilities in investment, nominal interest rate and inflation than is observed empirically, the results from the EDF model are closer to the data. Table 5 reports correlations between variables from the data and for the three models. The EDF model generates a correlation between nominal interest rate and inflation that is very close to the data, although it predicts lower correlations between the other variables. The DF model generates higher values for all the correlations except that between output and investment. The results for the NoFF model are similar to the DF model except that it underpredicts the correlations between output and the nominal interest rate and between output and inflation.

\subsection{Impulse responses}

In order to examine the effect of the imperfections in the debt and equity markets on model dynamics, we simulate the three economies EDF, DF and NoFF. ${ }^{16}$ Figures 4

\footnotetext{
${ }^{16}$ Since the data prefer the EDF model, the stochastic simulations in this section are based on the estimates of the EDF model.
} 
through 7 show the impulse responses to one standard deviation of investment-specific shock, technology shock, preference shock and monetary policy shock. Each variable's response is expressed as a percentage deviation from its steady-state level. Because we assume that monetary policy reacts to the deviation of output from the efficient output level, we plot responses in both output and the output gap.

Investment-efficiency shock Figure 4 shows the impulse responses to a one standard deviation of investment-efficiency shock. In response to the shock, final goods are now turned into investment goods more efficiently. As a result, investment increases and the price of capital falls. Since households spend more resources on investment, consumption decreases. To smooth fluctuations in consumption households increase the supply of labor. Thus hours increase and output rises. Inflation and nominal interest rate rise on impact.

Responses in the DF Model are "dampened" relative to the responses of the model without financial market frictions (the NoFF Model). Output, investment and hours still increase, but to a lesser degree. This is due to imperfections in the debt market. The decrease in asset price drives down net worth, which causes the external risk premium to rise. This dampens the response in investment, consumption, hours and output. Notice that net worth falls despite an increase in inflation. This indicates that the debt deflation effect is not dominant. Output falls below its potential due to the imperfections in the financial market.

In the model with both nominal debt and equity issuance costs (the EDF model), although the dampening effect of the financial accelerator still exists, output, investment and hours increases to a greater extent than in DF. This is due to the countercyclical nature of equity issuance costs. After a positive investment-specific shock, the issuance cost per unit of equity decreases, and capital producers increase capital production in response to this reduced cost. As a result, investment rises more and the asset price decreases much more. Households need to reduce consumption even more in order to increase investment spending. However, households are not willing to reduce consumption too much, thus in order to smooth consumption, households increase labor supply, which leads to an increase in output. Thus, on impact, we observe a positive output gap, and the overall deviation of output from its efficient level is less than in the DF model.

Technology shock Figure 5 presents the impulse responses to a one standard deviation of a technology shock. In the model without financial market frictions, output, investment, consumption and hours rise. Asset prices rise due to increased demand for capital. Both inflation and the nominal interest rate fall.

The DF Model shows that the financial accelerator dampens the responses of output, investment and asset prices slightly. This is due to the rise in external risk premium. ${ }^{17}$ Net worth increases despite the fact that inflation declines. This indicates again that the debt-deflation effect is not the effect dominating the dynamics of net worth. In the model with equity issuance costs (the EDF model), there is more dampening in output

\footnotetext{
${ }^{17}$ Risk premium and net worth rise at the same time. This is because leverage rises.
} 
and investment. Capital producers need to finance the increase in investment with costly equity; this additional cost pushes up the asset price and dampens the response in investment. In contrast to the investment-specific shock, the issuance cost per unit of equity has not changed. Overall, the distortions generated by the imperfections in the debt market and equity issuance market force output below the potential level. The distortions are more severe in the EDF model.

Preference shock The impulse responses to a one standard deviation of a preference shock are plotted in Figure 6. Following the shock, the marginal utility of consumption increases, which drives up the opportunity cost of savings. Households divert wealth saved in deposits to consumption. The decline in savings leads the nominal interest rate to increase and investment to fall. The increase in consumption leads households to reduce leisure so hours worked increase. Output rises due to the increase in hours. Asset prices decrease due to the fall in investment.

The impulse responses to a positive preference shock are almost identical in the DF Model and the EDF model except for the response of asset prices. ${ }^{18}$ Compared to the NoFF model, in both the DF Model and the EDF model, the presence of the financial accelerator dampens the decline in investment due to the decline in the external risk premium. However, the adjustment in investment is smoother in the model with equity since the equity issuance costs increase with investment. This reduces the deviation of output from its efficient level.

Monetary policy shock Finally, figure 7 plots the impulse responses to one standard deviation of monetary policy shock. After a contractionary monetary policy shock, the nominal interest rate rises. Output, investment, consumption, inflation and the supply of labor all fall on impact. The decrease in investment leads to a decline in the demand for capital, which leads to a lower asset price. Although the financial accelerator has a slight amplification effect, the responses in output, consumption and investment are almost identical in the DF Model and the NoFF model. This is because the external risk premium barely changes in the DF model. ${ }^{19}$ In the model with both debt and equity frictions, net worth drops much more, leading to a higher risk premium. However, the increase in risk premium is modest and the equity cost effect dominates the response of investment. That is, investment declines less than in the DF model because the cost of issuing equity decreases as investment falls. The declines in hours and output are also dampened.

To summarize, we find that the financial accelerator amplifies and propagates the effects of demand shocks (preference and monetary policy shocks) on investment and output, but dampens those of the supply shocks (technology and investment-specific

\footnotetext{
${ }^{18}$ Asset price tends to be more volatile in the model with equity issuance costs since it is more costly to adjust in this model.

${ }^{19}$ Note that both net worth and asset price decrease in this case and these two effects largely cancel each other out in their impact on the risk premium.
} 
shocks). ${ }^{20}$ These findings are similar to those in Christensen and Dib (2008) which also study the role of the financial accelerator mechanism with a nominal debt contract. However, regarding whether the dampening effect of the financial accelerator to the supply shocks is caused by debt-deflation effect, our model tells a different story. In Christensen and Dib (2008), after a positive technology shock, the decline in inflation increases the real cost of repaying existing debt, creating a debt-deflation effect. This debt-deflation effect dominates and forces net worth down. In our model, net worth increases. This is because after a positive technology shock, the rate of return on capital increases so much that it dominates debt-deflation effect and drives up net worth.

Overall, we show that the movement of the external risk premium is the driving force determining whether the financial accelerator has a amplification or a dampening effect. Following a positive supply shock, this financial accelerator mechanism leads to a negative output gap due to the dampening effect. Following a positive demand shock, it leads to a positive output gap due to the amplification effect. ${ }^{21}$ Equity issuance costs add another distortion to capital production, making capital adjustment more costly to all shocks except the investment-specific shock. Following demand shocks, this additional distortion dampens the response in investment, which helps to close the positive output gap. For the remaining supply shocks, technology shock and investment-specific shock, the effects of this distortion are different. Following a positive technology shock, this additional distortion drives output further below the potential. However, following an investment-specific shock, the countercyclical feature of equity issuance costs mitigates the dampening in investment. On impact we observe a positive output gap, and overall deviation of output from the efficient level is less than in the model with only debt market frictions.

\section{$5 \quad$ Price-level versus inflation targeting}

How would the real variables in the economy with financial market imperfections respond to the shocks in a price-level path targeting regime? Can a price-level targeting regime outperform the current inflation targeting regime in an economy with financial market imperfections? To answer these questions, in this section, we conduct stochastic simulations comparing these two regimes.

\subsection{PT versus IT with financial market imperfections: the benchmark case}

In the simulations, we assume that the only difference in the two economies is monetary policy: in one case the central bank follows an inflation targeting rule, while the other follows a price-level path rule. The behavioral parameters and the parameters governing

\footnotetext{
${ }^{20}$ Notice the amplification effect of monetary policy shock is only marginal. There is no propagation effect of monetary policy shock because we set interest rate smoothing parameter to 0 .

${ }^{21}$ Note that Figure 7 represents a positive interest rate shock, which should be considered a negative demand shock.
} 
the exogenous shocks do not vary between these two regimes; their values are taken from Table $2{ }^{22}$ For the coefficients in the inflation targeting rule, $\phi_{\pi}$ and $\phi_{y}$, we set them to the estimates $\phi_{\pi}=1.30$ and $\phi_{y}=0.015$. We do not have much knowledge of the values of the coefficients in the price-level path rule. Instead of identifying an optimal PT rule, which requires a utility-based welfare analysis, we provide a numerical example that sheds some light on how effective PT is in reducing the variability in output gap and inflation given the distortions in financial markets. In this example, we set $\phi_{p}=1.30$ and $\phi_{y}=0.015$, take it as our benchmark. In the next section, we varies these parameters to examine different PT rules. To evaluate these two rules, in Table 6 we report the standard deviations of key variables and the loss functions under the two rules, which are based on the weighted average of the variance of output gap and the variance of inflation: ${ }^{23}$

$$
\mathcal{L}=\frac{1}{2} \operatorname{var}\left(Y g a p-Y g a p_{s s}\right)+\frac{1}{2} \operatorname{var}\left(\pi_{t}-\pi_{s s}\right),
$$

where $Y$ gap $=Y_{t}-Y_{t}^{e}$ and $Y g a p_{s s}=Y_{s s}-Y_{s s}^{e}$. Since one of the natural questions arising with a price-level targeting regime is how long it should take for price level to return to target, we also report this horizon. ${ }^{24}$ We report the long-run forecast-error variance decompositions for output gap, inflation and nominal interest rate for both regimes in Table 7 .

Table 6 shows that compared to the economy under the IT rule, the economy under the PT rule has much less variability in inflation (36 percent of that under the IT rule) and slightly less variability in output gap (98 percent of that under the IT rule). The variability in price level under the PT rule is also very small, which explains the lower variability in the nominal interest rate. Overall, this PT rule reduces loss by 21 percent, and brings the price level back to target in 4 years.

Thus, for the benchmark case, PT can be a free lunch: inflation variability is not only reduced in the long-run but also in the short-run. This confirms the new view that in a forward-looking model, under PT inflation expectations operate as automatic stabilizers. Forward-looking agents understand that the central bank will offset disturbances to the price level and take this into account when they set today's prices, thus it is optimal for them to change prices by less. This also explains why real shocks (technology, investment

\footnotetext{
${ }^{22}$ The parameters of the model might not be invariant to the monetary policy rule. However, it is not obvious which of the parameters are likely to change and in which direction. Regarding uncertainty and monetary policy, see interesting discussions in Dib et al. (2008)

${ }^{23}$ The loss function can be represented in a more general form, $\mathcal{L}=\operatorname{var}\left(\widehat{Y g a p_{t}}\right)+\lambda \operatorname{var}\left(\pi_{t}-\pi_{s s}\right)$ with $0<\lambda<1$. We consider this equal weight loss function as the upper bound. The results of the PT-IT comparison can vary if we rank rules based welfare considerations rather than loss functions.

${ }^{24}$ Horizon is defined and computed in the following way. First, we plot the impulse response functions of the price level for each shock and compute the number of periods that it takes for the price level to return to the steady state. More specifically, we use the " 90 percent rule" to determine whether the steady-state has been reached. That is, once the price level recovers 90 percent from the peak of the deviation, we suppose that it has come back to the steady-state. Then we weigh each of the responses to come up with an aggregate response. For the weights, we use the contributions of the shocks to the variability of price level and normalize them to 1 . Note that another way of computing horizon is to use the stochastic simulation method of Basant Roi and Mendes (2007)
} 
and preference shocks) contribute little to variability in inflation and nominal interest rate under the $\mathrm{PT}$ rule.

However, given that there is not much stickiness in this economy (the estimated Calvo parameter is only 0.42) and that debt-deflation effect is not the dominating effect for the dynamics of net worth, the reduction in inflation variability has little impact on output gap variability. In fact, the changes in the nominal interest rate and inflation cancel out each other and leave the variability of real interest rate barely changed between the two regimes. The variance decompositions of output gap under the two regimes are also quite similar.

\subsection{The role of financial market imperfections in PT versus IT comparison}

Simulation results based on the benchmark model suggest that frictions in the debt and the equity markets have important effects on the dynamics of the model. Thus, policy recommendations based on different models (modeling frictions explicitly or ignoring the frictions) can potentially be different. In order to examine the policy question, we conduct the following experiments in this section: first, we compute variability in inflation and output gap for the EDF, DF and NoFF economies using the parameter values and monetary policy rules estimated separately for each economy in sections 4.1 and 4.2. Then, we assume that the three economies are subject to the same PT rule. We conduct stochastic simulations under different combinations of the parameters $\phi_{y}$ and $\phi_{p}$.

Tables 8 through 10 present the standard deviation of output gap and inflation, loss functions and horizons. Note that the standard deviations and loss are normalized with respect to their values in the corresponding IT cases. In what follows, we compare the results in the three tables.

We first focus on the common pattern. We observe in all the three models when the monetary authority responds to output gap very weakly, there is no trade-off between variability in output gap and inflation. That is, given low $\phi_{y}$, when the monetary authority responds more aggressively to price-level, both inflation and output gap becomes less volatile. However, when the monetary authority responds to output gap very aggressively $\left(\phi_{y}=1\right.$ and $\left.\phi_{y}=5\right)$, a trade-off between inflation and output gap starts to appear. Notice that horizon becomes substantivally longer in these cases since the monetary authority puts more weight on stabilizing output gap relative to price level. ${ }^{25} \mathrm{PT}$ delivers lower variability in inflation and smaller loss for most of the cases.

We now turn to the differences. The simulation results suggest that in general given the same PT rule, compared to the model EDF, the model ignoring both debt market imperfections and equity market imperfections predicts greater reductions in both variability in output gap and inflation, while the model ignoring equity issuance frictions

\footnotetext{
${ }^{25}$ Smets (2003) suggests that the optimal policy horizon for maintaining a price level objective is generally longer than that for achieving an inflation objective. In his benchmark case the optimal policy horizon under PT is 8 years.
} 
predicts lower reductions in both. Both the DF model and the NoFF model predict shorter horizons.

The intuition behind these results is as follows. In the NoFF model, most of the distortions come from the nominal rigidity in prices, that is, most of the variability in output gap is caused by inefficient price dispersion. In this model, reduction of inflation variability would automatically reduce output gap variability, so PT is most effective. In the models with financial market imperfections, the agency costs in the debt market and the equity issuance costs in the equity market create additional distortions. Due to the existence of these real frictions, reducing inflation variability does not necessarily lead to less variability in the output gap. The effectiveness of PT depends on the shock structure. For the shocks that drive inflation and output gap in the same direction, a monetary policy aimed at stabilizing inflation can still stabilize output gap. However, for the shocks that lead inflation and output gap to move in the opposite directions, the monetary authority faces a trade-off between output gap and inflation: when monetary authority tries to bring down inflation, the output gap widens. A positive investment-specific shock is an example of the latter type. Following a positive investment-specific shock, in the DF model, we observe a negative output gap and a rise in inflation. Frictions in the debt market prevent investment from rising as much as in the NoFF model, which causes output to fall below the potential. In the EDF model, following an investment-specific shock, the countercyclical feature of equity issuance costs mitigates the distortions generated in the debt market, and therefore output deviates from the efficient level to a lesser extent than in the DF model. Thus PT is more effective in the EDF model. These results suggest that the conclusions regarding the advantages of the PT regime versus the IT regime are dependent on the type of frictions/shocks being considered.

\section{Conclusions}

The objective of this paper is to compare the performance of two monetary policy regimes - price-level-path targeting and inflation targeting - in a standard New Keynesian model augmented with financial market imperfections. We find that introducing financial market imperfections brings new and important insights to the evaluation of these two monetary policy regimes.

Specifically, the contributions of the paper are as follows: first, we show that modeling financial market frictions, especially equity market frictions, enhances the model's fit to Canadian data, and that financial market frictions have important implications for model dynamics. Second, compared to the current IT regime, we show that PT can be a free lunch-that is, inflation variability is reduced not only in the long-run but also in the short-run. Third, we show that PT is most effective in reducing the distortions caused by nominal rigidities. Fourth, we show that given the existence of financial market frictions, the model ignoring those frictions can give misleading predictions regarding the gains (or the losses) arising from a switch to PT

There are several directions in which this paper could be extended. First, to better 
evaluate the performance of PT versus IT, a utility-based welfare analysis will be necessary. Second, given that we focus on the Canadian economy, a small open economy model could potentially fit the data better. ${ }^{26}$ Third, the fact that the debt-deflation effect is not significant may be due to the nominal debt contract only lasting one-period in our model. With longer contracts, we expect that different implications for the PT-IT comparison could emerge.

\footnotetext{
${ }^{26}$ A very recent paper by Dib et al. (2008) explores the desirability of price-level path targeting in a multi-sector small open economy with nominal debt contracts in both the domestic and international credit markets. Their policy implications are based on social welfare evaluations. However, equity market frictions are not modeled in their paper and the paper focuses on the role of financial shocks in the PT versus IT comparison rather than the role of financial market imperfections.
} 


\section{References}

Altinkiliç, Oya and Hansen, Robert S. (2000). Are there economies of scale in underwriting fees? evidence of rising external financing costs. The Review of Financial Studies 13, 191-218.

Amano, Robert and Murchison, Stephen. (2000). Factor-market structure, shifting inflation targets, and the new keynesian phillips curve. Bank of Canada Conference, April 2005 .

Basant Roi, M and R. Mendes. (2007). Should central banks adjust their target horizons in response to house-price bubbles? Discussion Paper 200\%-4, Bank of Canada.

Bernanke, Ben and Gertler, Mark and Gilchrist, Simon. (1999). The financial accelerator in a quantitative business cycle framework. In J. Taylor and M. Woodford (Eds.), Handbook of Macroeconomics, pp. 1341-93. Elsevier Science B.V.

Calvo, Guillermo A. (1983). Staggered prices in a utility-maximizing framework. Journal of Monetary Economics 12, 383-398.

Carlstrom, Charles T. and Fuerst, Timothy S. (1997). Agency costs, net worth, and business fluctuations: A computable general equilibrium analysis. American Economic Review 87, 893-910.

Choe, Hyuk and Masulis, Ronald W. and Nanda, Vikram. (1993). Common stock offerings across the business cycle. Journal of Empirical Finance 1, 3-31.

Christensen, Ian and Dib, Ali. (2008). The financial accelerator in an estimated new keynesian model. Review of Economic Dynamics 11, 155-178.

Christiano, Larry J. and Motto, Roberto and Rostagno, Massimo. (2003). The great depression and the friedman-schwartz hypothesis. Journal of Money Credit and Banking 35, 1119-1197.

Coletti, Donald and Lalonde, Rene and Muir, Dirk. (2008). Inflation targeting and pricelevel-path targeting in the gem: Some open economy considerations. Bank of Canada WP 2008-6.

Covas, Francisco and den Haan, Wouter J. (2006). The role of debt and equity finance over the business cycle. Bank of Canada WP 2006-46.

(2007). The cyclical behavior of debt and equity: Evidence from a panel of canadian firms. Manuscript, Bank of Canada and University of Amsterdam.

Dib, Ali and Mendicino, Caterina and Zhang, Yahong. (2008). Price level targeting in a small open economy with financial frictions: Welfare analysis. Manuscript, Bank of Canada. 
Duguay, Pierre. (1994). Some thoughts on price stability versus zero inflation. Mimeo, Bank of Canada.

Fama, Eugene F. and French, Kenneth R. (2005). Financing decisions: Who issues stock? Journal of Financial Economics 76, 549-82.

Gilchrist, Simon and Saito, Masashi. (2006). Expectations, asset prices, and monetary policy: The role of learning. In J. Campbell (Ed.), Asset Prices and Monetary Policy. University of Chicago, Forthcoming.

Jermann, Urban and Quadrini, Vincenzo. (2006). Financial innovations and macroeconomic volatility. NBER Working Paper No. 12308.

Levy, Amnon and Hennessy, Christopher. (2006). Why does capital structure choice vary with macroeconomic conditions? Journal of Monetary Economics. 54, 1545-64.

Meh, Césaire and Ríos-Rull, José-Víctor and Terajima, Yaz. (2008). Aggregate and welfare effects of redistribution of wealth under inflation and price-level targeting. Manuscript, Bank of Canada.

Schmitt-Grohé, Stephanie and Uribe, Martín. (2006). Optimal fiscal and monetary policy in a medium-scale macroeconomic model. In M. Gertler and K. Rogoff (Eds.), Macroeconomics Annual 2005. Cambridge MA: MIT Press: Cambridge MA.

Smets, Frank. (2003). Maintaining price stability: How long is the medium term? Journal of Monetary Economics 50, 1293-1309.

Svensson, Lars E.O. (1999). Price level targeting vs. inflation targeting: a free lunch? Journal of Money Credit and Banking 31, 277-295.

Vestin, David. (2006). Price-level versus inflation targeting. Journal of Monetary Economics 53, 1361-1376.

Woodford, Michael. (2003). Interest and Prices: Foundations of a Theory Monetary Policy. Princeton and Oxford: Princeton University Press. 
Table 1: Parameter Calibration

\begin{tabular}{clc}
\hline \hline Parameters & Definition & Values \\
\hline$\beta$ & discount factor & 0.99 \\
$\delta$ & capital depreciation rate & 0.025 \\
$\alpha$ & capital share in production function & $1 / 3$ \\
$\varepsilon$ & intermediate-good elasticity of substitution & 11 \\
$\gamma$ & inverse of labor supply elasticity & 0.8 \\
$\theta$ & weight on leisure in the utility function & 0.195 \\
$\eta$ & survival rate of entrepreneurs & 0.9728 \\
$\pi$ & gross steady-state inflation rate & 1.005 \\
$n / k$ & steady-state ratio of net worth to capital & 0.6 \\
$s$ & gross steady-state risk premium & 1.0177 \\
\hline
\end{tabular}


Table 2: Estimation Results

\begin{tabular}{|c|c|c|c|c|c|c|c|}
\hline \multirow[b]{2}{*}{ Coef. } & \multicolumn{3}{|c|}{ Prior Distribution } & \multicolumn{4}{|c|}{ Posterior Distribution } \\
\hline & Density & Mean & Std & Mode & Mean & 5 percent & 95 percent \\
\hline$\chi$ & $\mathrm{G}$ & 0.05 & 0.01 & 0.042 & 0.043 & 0.029 & 0.058 \\
\hline$\lambda_{0}$ & $\mathrm{G}$ & 0.75 & 0.10 & 0.92 & 0.93 & 0.76 & 1.11 \\
\hline$\lambda_{1}$ & $\mathrm{G}$ & 20.0 & 2.0 & 19.64 & 19.78 & 16.49 & 22.93 \\
\hline$\xi$ & $\mathrm{N}$ & 0.25 & 0.05 & 0.26 & 0.26 & 0.18 & 0.34 \\
\hline$\nu$ & $\mathrm{B}$ & 0.67 & 0.05 & 0.42 & 0.43 & 0.39 & 0.48 \\
\hline$\phi_{\pi}$ & G & 1.50 & 0.10 & 1.30 & 1.33 & 1.22 & 1.43 \\
\hline$\phi_{Y}$ & $\mathrm{~N}$ & 0.10 & 0.02 & 0.015 & 0.009 & -0.022 & 0.044 \\
\hline$\rho_{z}$ & B & 0.80 & 0.05 & 0.76 & 0.75 & 0.69 & 0.82 \\
\hline$\rho_{x}$ & B & 0.80 & 0.05 & 0.88 & 0.87 & 0.83 & 0.92 \\
\hline$\rho_{p}$ & B & 0.80 & 0.05 & 0.87 & 0.87 & 0.83 & 0.91 \\
\hline$\sigma_{z}$ & $\mathrm{IG}$ & 0.01 & - & 0.0114 & 0.0117 & 0.0101 & 0.0134 \\
\hline$\sigma_{e}$ & $\mathrm{IG}$ & 0.01 & - & 0.0067 & 0.0068 & 0.0061 & 0.0076 \\
\hline$\sigma_{x}$ & $\mathrm{IG}$ & 0.01 & - & 0.0057 & 0.0060 & 0.0045 & 0.0075 \\
\hline$\sigma_{p}$ & $\mathrm{IG}$ & 0.01 & - & 0.0147 & 0.0150 & 0.0132 & 0.0170 \\
\hline
\end{tabular}


Table 3: Model Comparison: Likelihood

\begin{tabular}{cccccccc}
\hline \hline & \multicolumn{3}{c}{ Prior } & & \multicolumn{3}{c}{ Posterior Mode } \\
\cline { 1 - 4 } Coef. & Density & Mean & Std & & EDF & DF & NoFF \\
\hline$\chi$ & $\mathrm{G}$ & 0.05 & 0.01 & & 0.042 & 0.065 & - \\
$\lambda_{0}$ & $\mathrm{G}$ & 0.75 & 0.10 & & 0.92 & - & - \\
$\lambda_{1}$ & $\mathrm{G}$ & 20.0 & 2.0 & & 19.64 & - & - \\
$\xi$ & $\mathrm{N}$ & 0.25 & 0.05 & & 0.26 & 0.31 & 0.32 \\
$\nu$ & $\mathrm{B}$ & 0.67 & 0.05 & & 0.42 & 0.34 & 0.34 \\
\hline$\phi_{\pi}$ & $\mathrm{G}$ & 1.50 & 0.10 & & 1.30 & 1.24 & 1.13 \\
$\phi_{Y}$ & $\mathrm{~N}$ & 0.10 & 0.02 & & 0.015 & 0.032 & 0.065 \\
\hline$\rho_{z}$ & $\mathrm{~B}$ & 0.80 & 0.05 & & 0.76 & 0.80 & 0.84 \\
$\rho_{x}$ & $\mathrm{~B}$ & 0.80 & 0.05 & & 0.88 & 0.89 & 0.91 \\
$\rho_{p}$ & $\mathrm{~B}$ & 0.80 & 0.05 & & 0.87 & 0.88 & 0.90 \\
$\sigma_{z}$ & $\mathrm{IG}$ & 0.01 & - & 0.0114 & 0.0097 & 0.0095 \\
$\sigma_{e}$ & $\mathrm{IG}$ & 0.01 & - & 0.0067 & 0.0070 & 0.0072 \\
$\sigma_{x}$ & $\mathrm{IG}$ & 0.01 & - & 0.0057 & 0.0125 & 0.0076 \\
$\sigma_{p}$ & $\mathrm{IG}$ & 0.01 & - & 0.0147 & 0.0145 & 0.0131 \\
\hline \multicolumn{3}{c}{ log data } & density & & 1292.77 & 1255.78 & 1247.02 \\
\hline
\end{tabular}


Table 4: SDs and Relative Volatilities: Data and Models

\begin{tabular}{lcccc}
\hline \hline & Data & EDF & DF & NoFF \\
\hline Standard & deviations \\
\hline Output & 0.040 & 0.030 & 0.033 & 0.036 \\
Investment & 0.134 & 0.121 & 0.150 & 0.177 \\
Nominal interest rate & 0.0086 & 0.0071 & 0.0082 & 0.0100 \\
Inflation & 0.0047 & 0.0061 & 0.0083 & 0.0100 \\
Output gap & - & 0.0119 & 0.0196 & 0.0079 \\
\hline \multicolumn{5}{c}{ Relative volatilities } \\
\hline Output & 1 & 1 & 1 & 1 \\
Investment & 3.25 & 4.03 & 4.55 & 4.92 \\
Nominal interest rate & 0.22 & 0.24 & 0.25 & 0.28 \\
Inflation & 0.12 & 0.20 & 0.25 & 0.28 \\
\hline
\end{tabular}


Table 5: Correlations: Data and Models

\begin{tabular}{lcccc}
\hline \hline & Data & EDF & DF & NoFF \\
\hline Output, investment & 0.82 & 0.70 & 0.74 & 0.73 \\
Output, nom. int. rate & 0.29 & 0.13 & 0.37 & 0.20 \\
Output, inflation & 0.39 & 0.31 & 0.48 & 0.33 \\
Investment, nominal interest rate & 0.32 & 0.20 & 0.45 & 0.42 \\
Investment, inflation & 0.44 & 0.40 & 0.61 & 0.56 \\
Nominal interest rate, inflation & 0.61 & 0.62 & 0.75 & 0.82 \\
\hline
\end{tabular}


Table 6: PT versus IT: Benchmark

\begin{tabular}{lccc}
\hline & \multicolumn{2}{c}{ Inflation targeting } & Price-level targeting \\
\hline Loss function & 0.000179 & 0.000142 & 0.79 \\
Horizon (in years) & - & 4.0 & - \\
\hline \multicolumn{4}{c}{ Otandard deviations of key variables } \\
\hline Inflation & 0.0119 & 0.0117 & 0.98 \\
Price level & 0.0061 & 0.0022 & 0.36 \\
Nominal interest rate & - & 0.0023 & - \\
Real int. rate & 0.0074 & 0.0051 & 0.69 \\
\hline
\end{tabular}


Table 7: Long-run Forecast Error Variance Decompositions: Benchmark

\begin{tabular}{lcccc}
\hline \hline \multicolumn{5}{c}{ Inflation Targeting } \\
\hline Variable & Technology & Mon Policy & Investment & Preference \\
\hline Output gap & 29.1 & 30.2 & 25.7 & 15.1 \\
Inflation & 18.8 & 27.7 & 33.7 & 19.8 \\
Nominal interest rate & 23.5 & 11.8 & 40.4 & 24.3 \\
\hline \multicolumn{5}{c}{ Price-level-path Targeting } \\
\hline Variable & Technology & Mon Policy & Investment & Preference \\
Output gap & 29.4 & 26.6 & 28.7 & 15.4 \\
Inflation & 3.3 & 87.6 & 7.4 & 1.6 \\
Nominal interest rate & 5.0 & 82.4 & 8.5 & 4.2 \\
\hline
\end{tabular}


Table 8: Simulation Results on PT: the EDF Model

\begin{tabular}{|c|c|c|c|c|c|c|}
\hline \multicolumn{7}{|c|}{ Standard Deviation of Output Gap } \\
\hline & $\phi_{y}=0.00$ & $\phi_{y}=0.015$ & $\phi_{y}=0.03$ & $\phi_{y}=0.06$ & $\phi_{y}=1.0$ & $\phi_{y}=5.0$ \\
\hline$\phi_{p}=1$ & 1.018 & 1.010 & 1.002 & 0.986 & 0.805 & 0.721 \\
\hline$\phi_{p}=2$ & 0.952 & 0.947 & 0.942 & 0.934 & 0.815 & 0.744 \\
\hline$\phi_{p}=5$ & 0.885 & 0.884 & 0.882 & 0.879 & 0.823 & 0.768 \\
\hline \multicolumn{7}{|c|}{ Standard Deviation of Inflation } \\
\hline$\phi_{p}=1$ & 0.401 & 0.394 & 0.387 & 0.374 & 0.319 & 0.705 \\
\hline$\phi_{p}=2$ & 0.303 & 0.299 & 0.294 & 0.286 & 0.237 & 0.502 \\
\hline$\phi_{p}=5$ & 0.186 & 0.184 & 0.182 & 0.179 & 0.151 & 0.312 \\
\hline \multicolumn{7}{|c|}{ Loss Function } \\
\hline$\phi_{p}=1$ & 0.854 & 0.841 & 0.826 & 0.799 & 0.535 & 0.516 \\
\hline$\phi_{p}=2$ & 0.736 & 0.729 & 0.721 & 0.707 & 0.538 & 0.490 \\
\hline$\phi_{p}=5$ & 0.628 & 0.626 & 0.623 & 0.618 & 0.541 & 0.487 \\
\hline \multicolumn{7}{|c|}{ Horizon (in Years) } \\
\hline$\phi_{p}=1$ & 4.6 & 4.4 & 4.2 & 10.2 & 35.6 & 37.4 \\
\hline$\phi_{p}=2$ & 3.4 & 3.2 & 3.1 & 6.8 & 34.2 & 36.3 \\
\hline$\phi_{p}=5$ & 2.3 & 2.2 & 2.1 & 2.2 & 31.7 & 34.9 \\
\hline
\end{tabular}


Table 9: Simulation Results on PT: the DF Model

\begin{tabular}{|c|c|c|c|c|c|c|}
\hline \multicolumn{7}{|c|}{ Standard Deviation of Output Gap } \\
\hline & $\phi_{y}=0.00$ & $\phi_{y}=0.01$ & $\phi_{y}=0.032$ & $\phi_{y}=0.065$ & $\phi_{y}=1.0$ & $\phi_{y}=5.0$ \\
\hline$\phi_{p}=1$ & 1.072 & 1.066 & 1.058 & 1.045 & 0.908 & 0.791 \\
\hline$\phi_{p}=2$ & 1.027 & 1.024 & 1.021 & 1.014 & 0.935 & 0.848 \\
\hline$\phi_{p}=5$ & 0.995 & 0.994 & 0.993 & 0.991 & 0.958 & 0.902 \\
\hline \multicolumn{7}{|c|}{ Standard Deviation of Inflation } \\
\hline$\phi_{p}=1$ & 0.514 & 0.506 & 0.498 & 0.485 & 0.609 & 1.638 \\
\hline$\phi_{p}=2$ & 0.358 & 0.353 & 0.348 & 0.339 & 0.373 & 0.996 \\
\hline$\phi_{p}=5$ & 0.189 & 0.188 & 0.186 & 0.184 & 0.194 & 0.502 \\
\hline \multicolumn{7}{|c|}{ Loss Function } \\
\hline$\phi_{p}=1$ & 1.015 & 1.002 & 0.987 & 0.962 & 0.755 & 0.939 \\
\hline$\phi_{p}=2$ & 0.914 & 0.908 & 0.902 & 0.889 & 0.762 & 0.761 \\
\hline$\phi_{p}=5$ & 0.845 & 0.843 & 0.841 & 0.838 & 0.784 & 0.729 \\
\hline \multicolumn{7}{|c|}{ Horizon (in Years) } \\
\hline$\phi_{p}=1$ & 2.9 & 2.9 & 2.6 & 2.8 & 14.1 & 15.8 \\
\hline$\phi_{p}=2$ & 2.1 & 2.0 & 1.8 & 2.2 & 13.7 & 15.1 \\
\hline$\phi_{p}=5$ & 1.6 & 1.5 & 1.34 & 1.5 & 13.2 & 14.8 \\
\hline
\end{tabular}


Table 10: Simulation Results on PT: the NoFF Model

\begin{tabular}{|c|c|c|c|c|c|c|}
\hline \multicolumn{7}{|c|}{ Standard Deviation of Output Gap } \\
\hline & $\phi_{y}=0.00$ & $\phi_{y}=0.015$ & $\phi_{y}=0.03$ & $\phi_{y}=0.06$ & $\phi_{y}=1.0$ & $\phi_{y}=5.0$ \\
\hline$\phi_{p}=1$ & 1.240 & 1.211 & 1.179 & 1.122 & 0.474 & 0.148 \\
\hline$\phi_{p}=2$ & 0.884 & 0.867 & 0.850 & 0.818 & 0.406 & 0.150 \\
\hline$\phi_{p}=5$ & 0.490 & 0.485 & 0.479 & 0.469 & 0.303 & 0.152 \\
\hline \multicolumn{7}{|c|}{ Standard Deviation of Inflation } \\
\hline$\phi_{p}=1$ & 0.428 & 0.419 & 0.411 & 0.394 & 0.202 & 0.143 \\
\hline$\phi_{p}=2$ & 0.300 & 0.296 & 0.290 & 0.281 & 0.157 & 0.106 \\
\hline$\phi_{p}=5$ & 0.160 & 0.159 & 0.157 & 0.154 & 0.103 & 0.068 \\
\hline \multicolumn{7}{|c|}{ Loss Function } \\
\hline$\phi_{p}=1$ & 0.704 & 0.672 & 0.638 & 0.579 & 0.111 & 0.021 \\
\hline$\phi_{p}=2$ & 0.356 & 0.343 & 0.329 & 0.306 & 0.078 & 0.016 \\
\hline$\phi_{p}=5$ & 0.108 & 0.106 & 0.104 & 0.099 & 0.042 & 0.012 \\
\hline \multicolumn{7}{|c|}{ Horizon (in Years) } \\
\hline$\phi_{p}=1$ & 3.5 & 3.6 & 3.8 & 4.1 & 9.1 & 13.9 \\
\hline$\phi_{p}=2$ & 2.4 & 2.5 & 2.6 & 2.9 & 7.2 & 12.8 \\
\hline$\phi_{p}=5$ & 1.7 & 1.8 & 1.8 & 1.9 & 5.0 & 11.5 \\
\hline
\end{tabular}


Figure 1: Prior and Posterior distribution of the model.
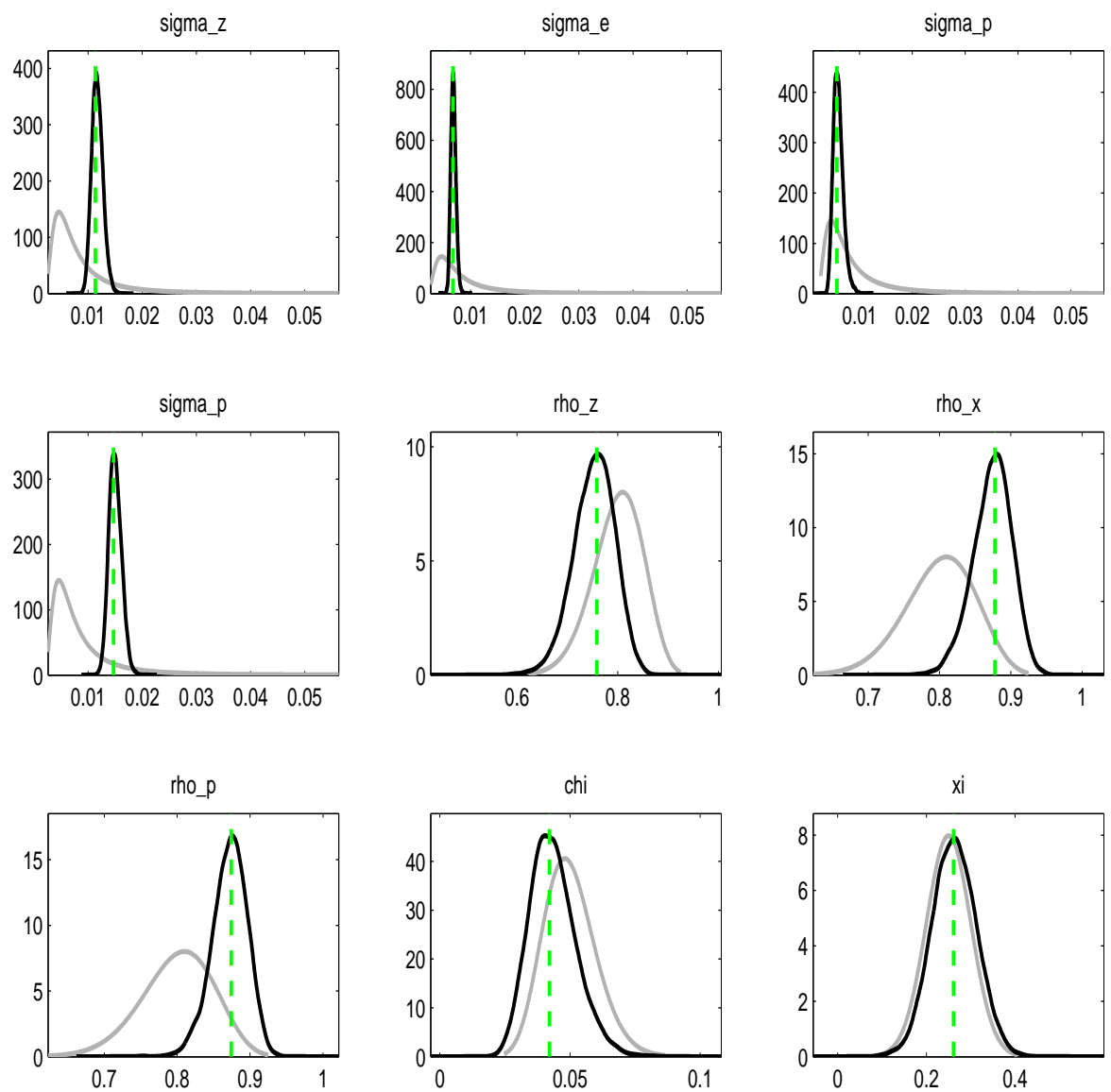
Figure 2: Prior and Posterior distribution of the model.
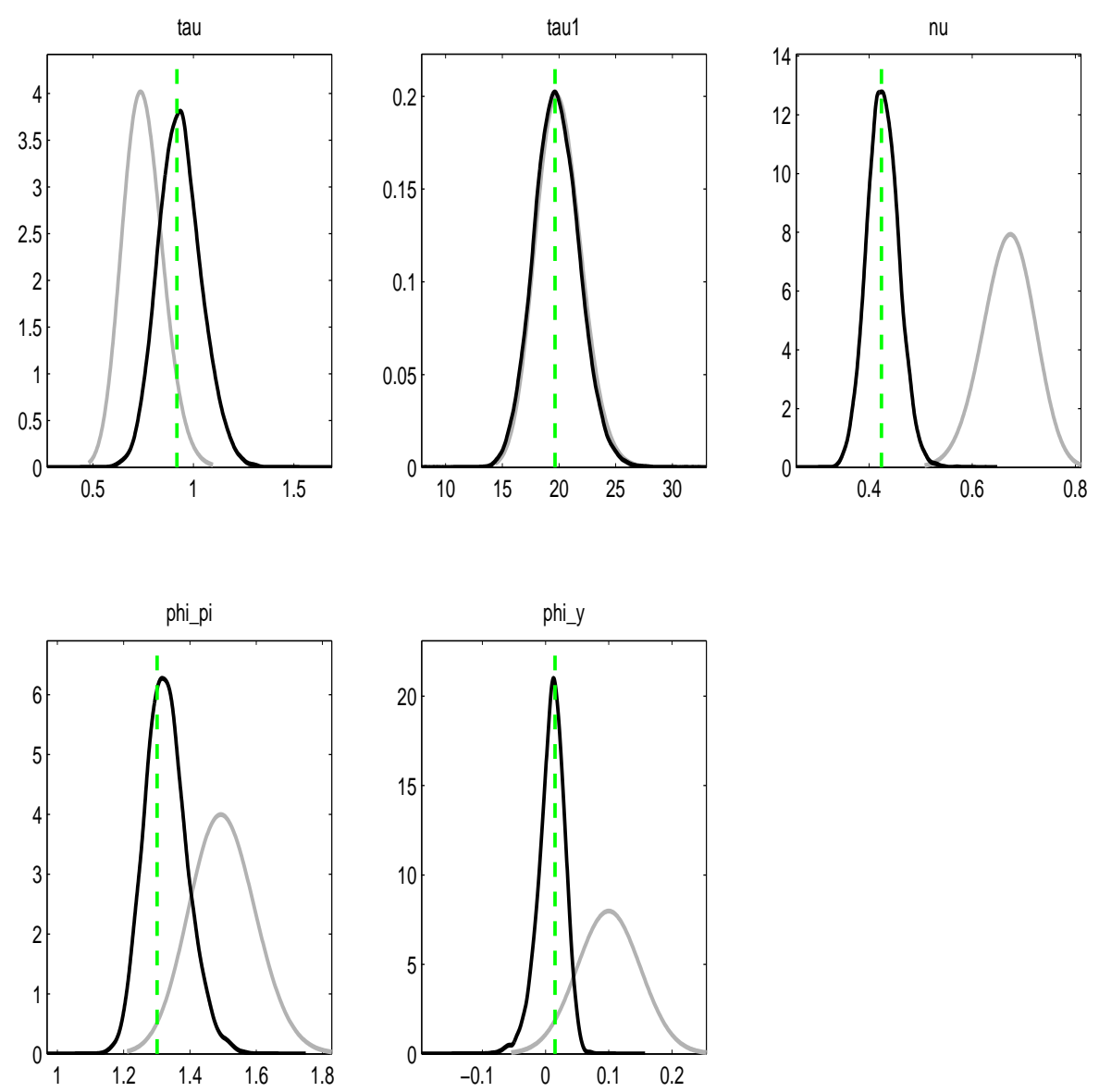
Figure 3: Smoothed shocks.
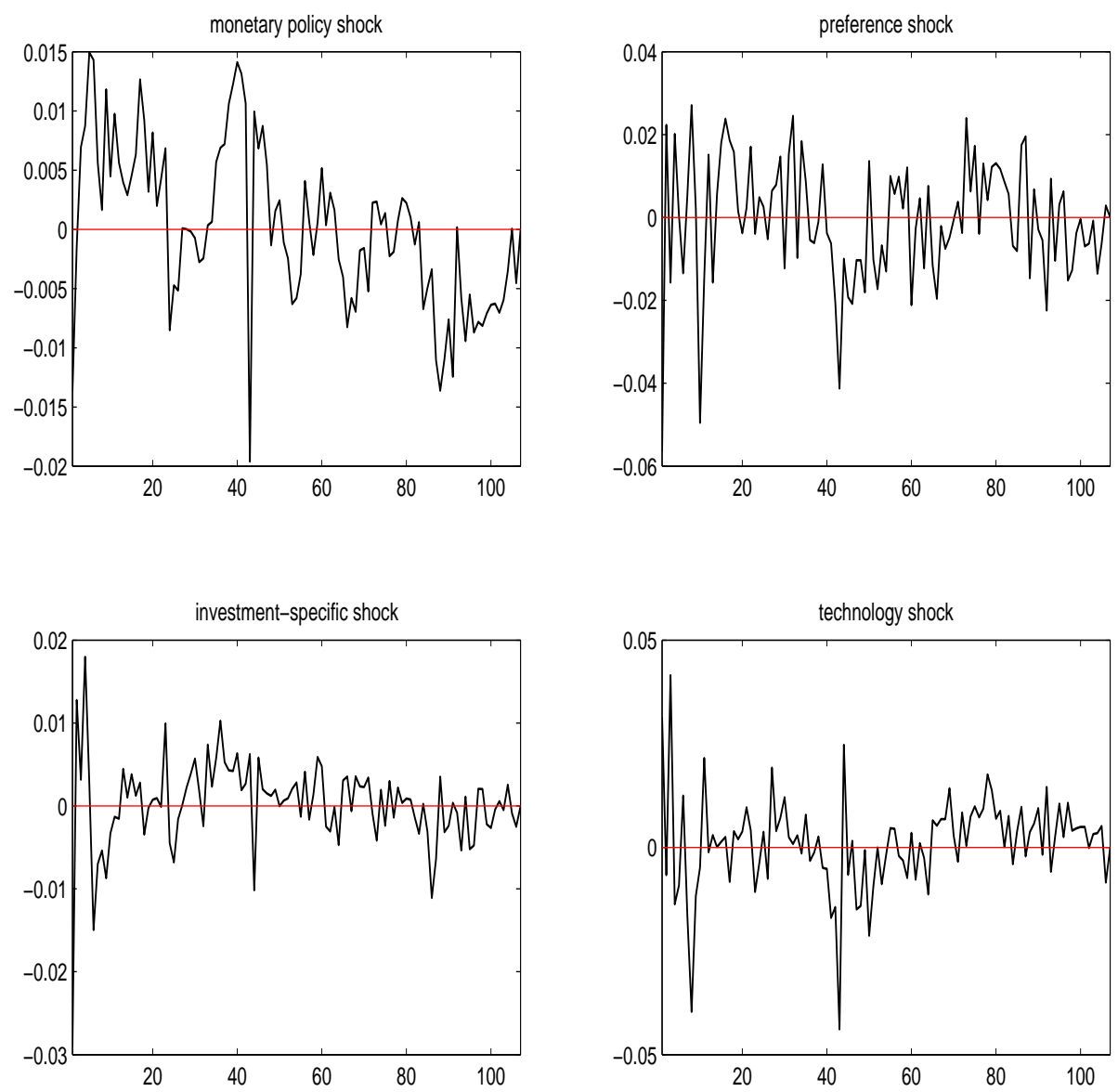
Figure 4: Responses to a Positive Investment-Specific Shock.
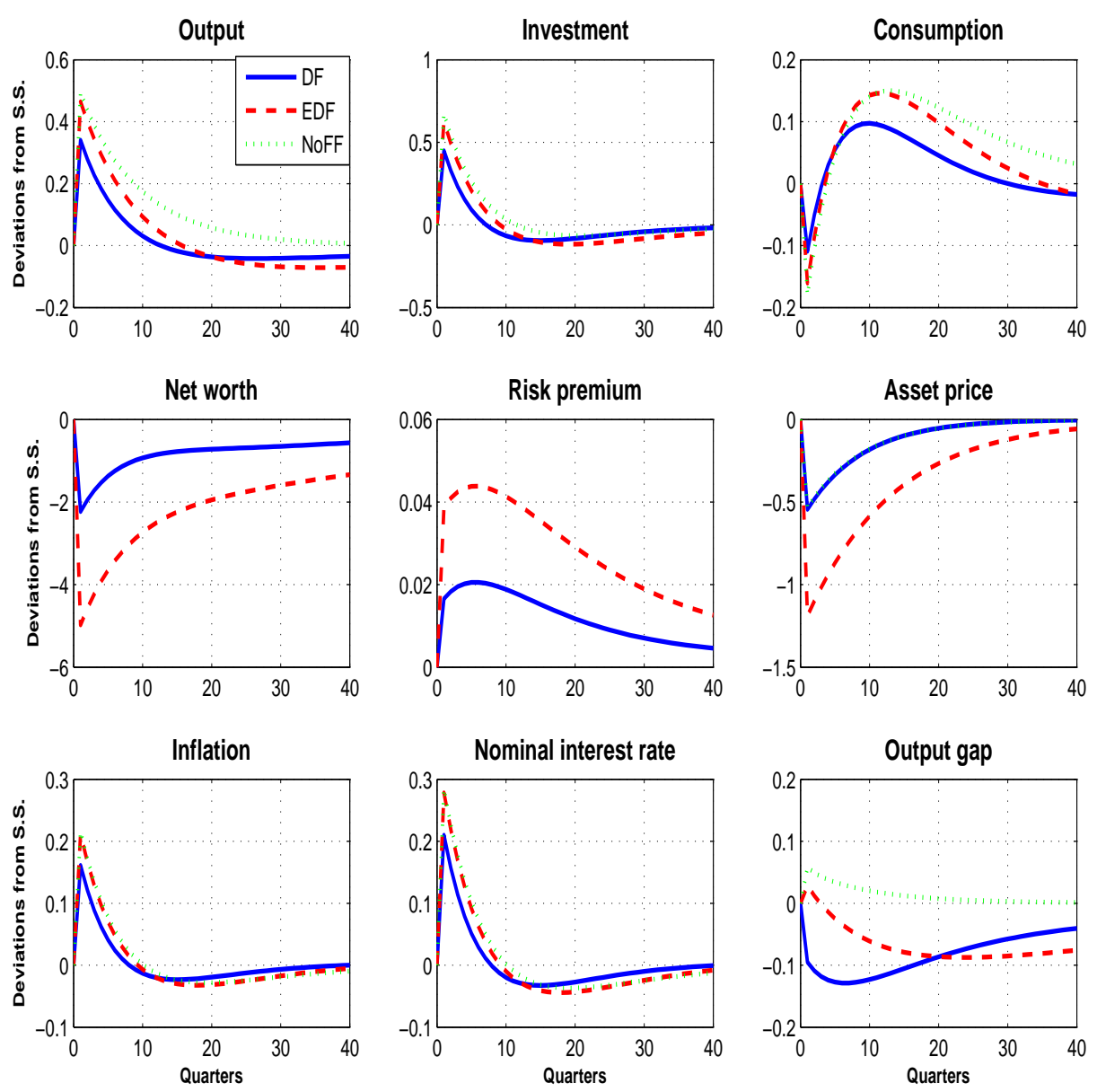
Figure 5: Responses to a Positive Technology Shock
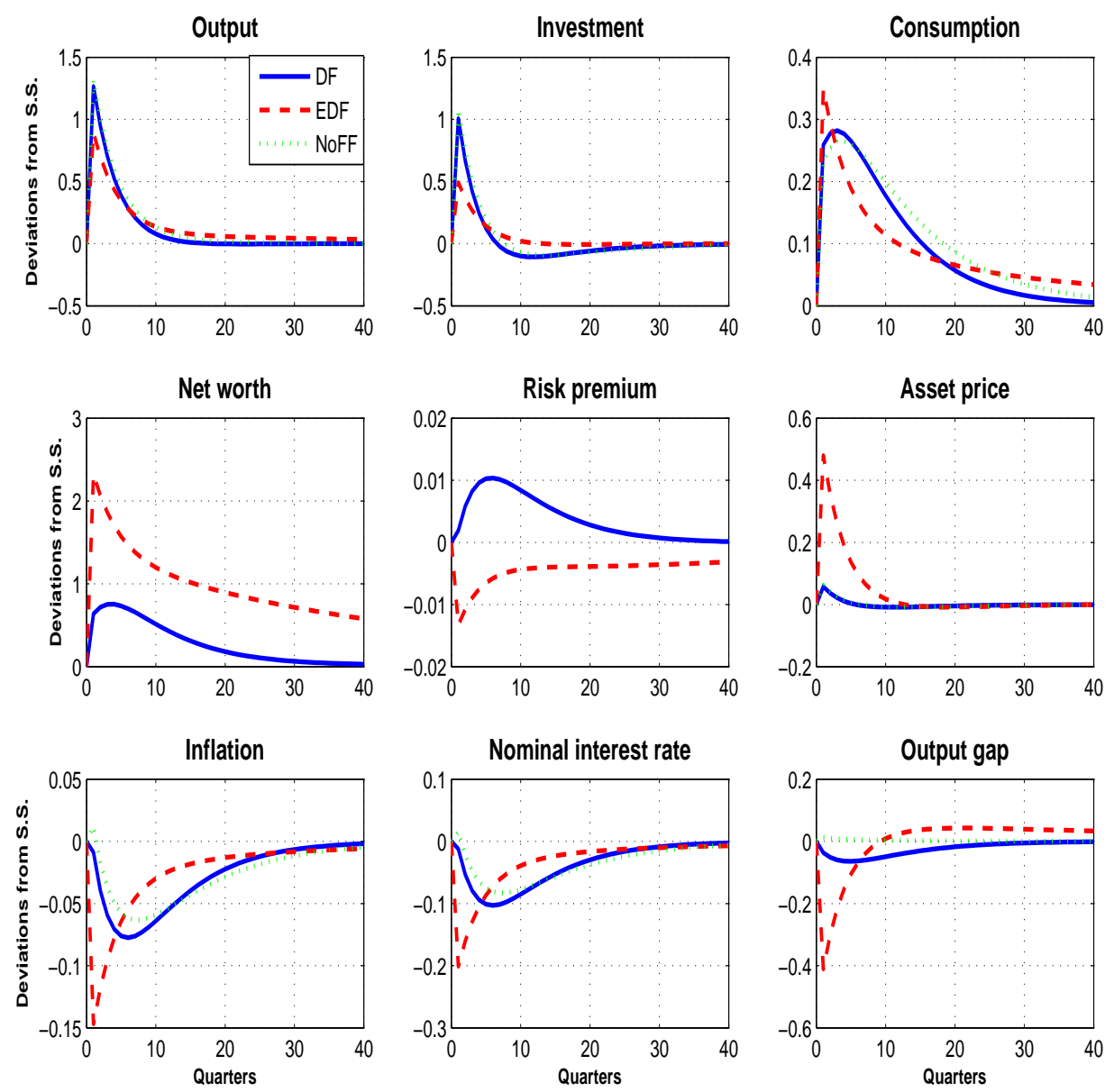
Figure 6: Responses to a Positive Preference Shock
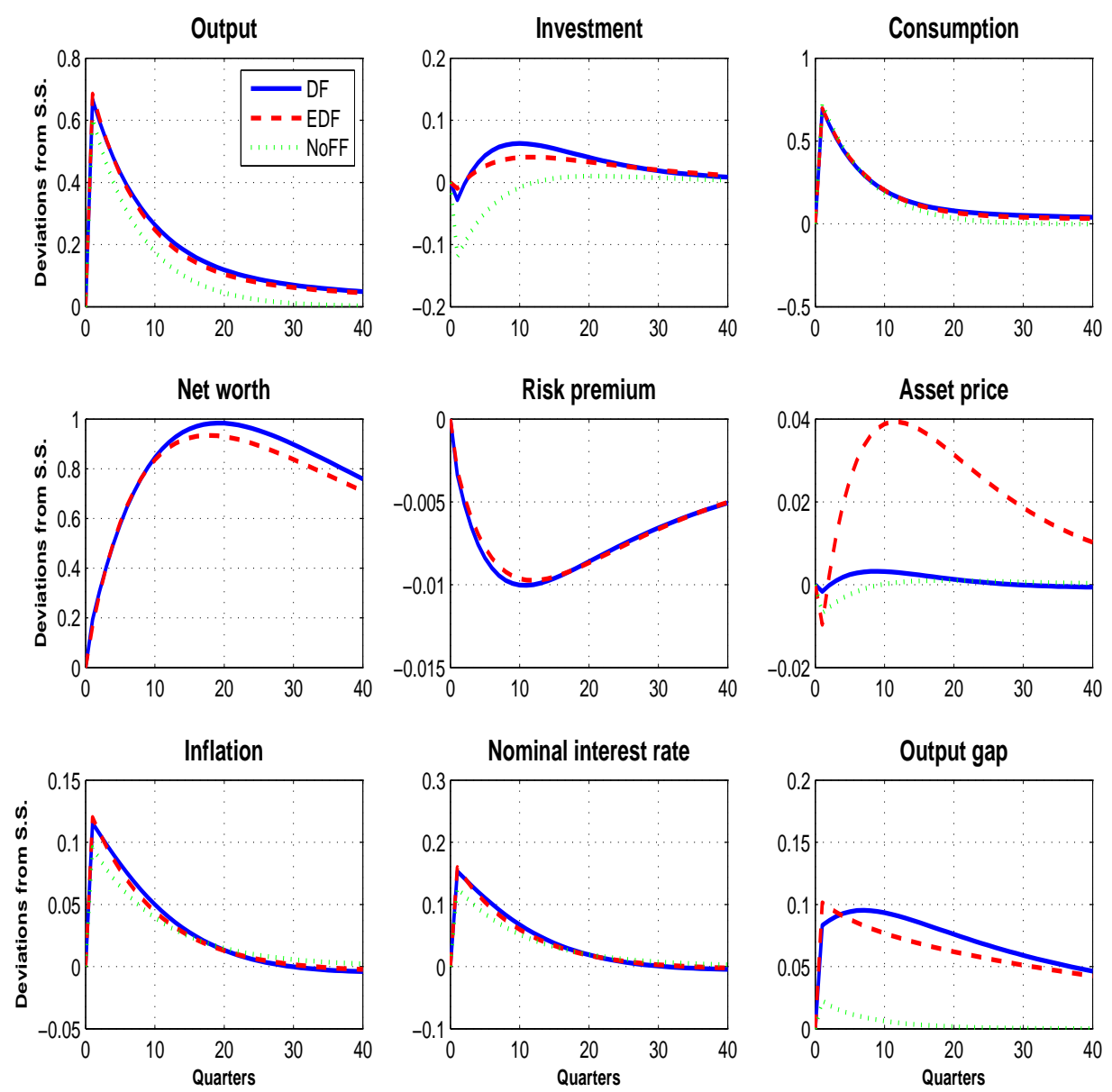
Figure 7: Responses to a Contractionary Monetary Policy Shock
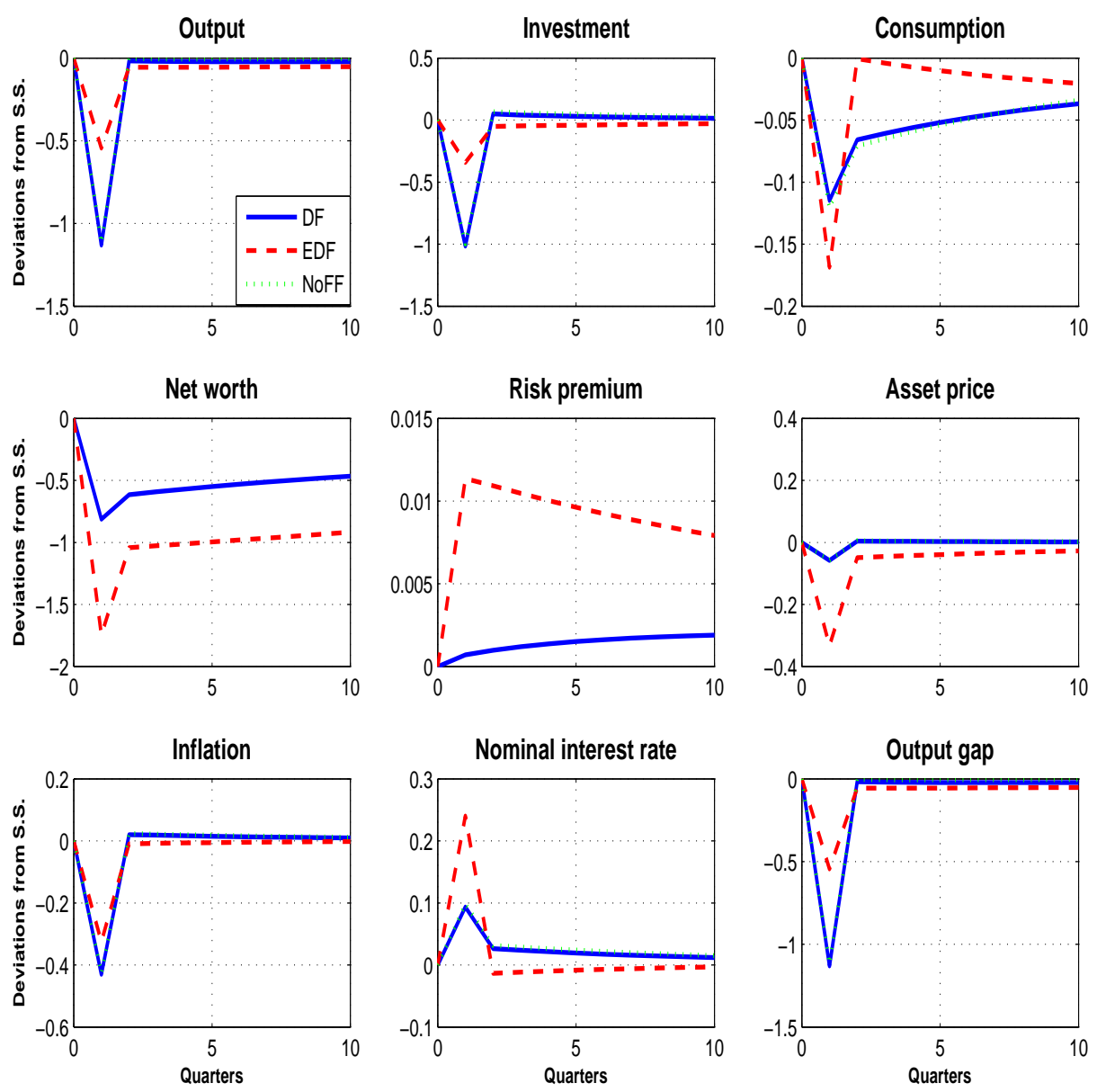